\title{
Study of total phenol, flavonoid contents and phytochemical screening of methanolic crude extracts of two weed plants
}

Shah Shreshtha ${ }^{1}$, Jain Anushi ${ }^{1}$, Joshi Ambika ${ }^{2 *}$ Joshi Nitesh $^{2}$, Harshal Anupma $^{3}$

1,3Kishinchand Chellaram College, Churchgate, Mumbai, Maharashtra 400020, India.

2 Jai Hind College, Churchgate, Mumbai, Maharashtra 400020, India.

${ }^{2}$ Rizvi College, Bandra West, Mumbai, Maharashtra 400050, India.

Received: 2017-05-23; Accepted: 2017-05-26

\begin{abstract}
Weeds have been neglected and their use for medicinal purpose has not been considered on a large scale. Our current research was based on the phytochemical Screening of Ipomoea carnea and Alternanthera sessilis and to quantitatively evaluate their total phenolic and flavonoid content. Quantitative analysis of Phenols and Flavonoids was done by the Folin Ciocalteau and Aluminium chloride method respectively. Both weeds showed positive response for presence of secondary metabolites like flavonoids, phenols, tannins, terpenoids, proteins, carbohydrates, etc. which indicates that they can be used as herbal components. The total Phenol value of Ipomoea carnea and Alternanthera sessilis was 0.0526 and $0.0657 \mathrm{mg}$ Gallic acid equivalent/g respectively. The flavonoid content value of Ipomoea carnea and Alternanthera sessilis was 0.09 and $0.2 \mathrm{mg}$ quercetin equivalent (QE) / $\mathrm{g}$ respectively. Both the weeds showed presence of several phytochemicals and high Phenol and Flavonoid values. However, Alternanthera showed a higher concentration of Phenols and Flavonoids as compared to Ipomoea. Since both the selected weeds grow in many areas throughout the world, their medicinal properties can be exploited and used for several applications. With the continuous use of antibiotics, microorganisms have become resistant. There is a need to develop alternative antimicrobial drugs using weeds, which otherwise have not been exploited till now by humans.
\end{abstract}

Keywords: Alternanthera; Flavonoid Content; Ipomoea; Phenol Content; Phytochemicals.

\section{Introduction}

Weeds are plants which do not have any specific requirement with respect to climatic conditions, nutrients, space. They grow at disturbed and inhabited places. Weeds are useful to human beings as food, erosion control, medicines, aesthetic value, shelter, supply of organic matter and mineral nutrients to the soil. (Jain A. et al., 2016) They possess a large number of medicinal properties which otherwise are not explored. These medicinal properties areby the virtue of their phytochemicals that they are used as therapeutic agents. Traditional healers recognized their medicinal potential and have utilized them for the treatment of human ailments. Weeds are also found to be resistant to most of the microbial diseases when compared to the cultivated crops. (Udaya Prakash NK, 2013) Ipomoea carnea and Alternanthera sessilis are two common weeds in India. Ipomoea Carneais one common weed popularly known as Besharam. It has been identified as a useful material for several applications including medicinal purposes. It is commonly used for treating Safed Dag (Leucoderma). (Sharma A, 2013) Alternanthera sessilis is a perennial herb that inhabits many areas of the world. A. sessilis is used internally against intestinal inflammation, externally to treat wounds, to treat hepatitis, tight chest, bronchitis, asthma, lung troubles, to stop bleeding and as a hair tonic (Singh A, 2009). A plant produces some chemical

*Corresponding Author:

Dr. Joshi Ambika,

Jai Hind College, Churchgate,

Mumbai, Maharashtra 400020, India.

E-mail: ambikapurijoshi@gmail.com compounds that are released into the environment called as allelochemicals. These allelochemicals shows positive or negative effects on seed germination, growth and development of other plants. The stimulatory or inhibitory effect of one plant to another plant is called allelopathic effect. (Abhinav A. Mali, et al., 2014). Allelopathy of $I$. carnea has been proposed as a strong mechanism for their remarkable success over the native species, which may be devoid of these innate allelopathic potentials and it has agro-ecological applications that helps in developing more environmentally friendly synthetic herbicides. (Mohamed Abd ElAalLotfySadek, 2014) Both the plants species are proven to show allelopathic effect. (Nitesh Joshi, et al., 2015)

Bioactive compounds in plants are known to be responsible for various bioactivities of the plant. Correlation between these bioactive compounds and the bioactivity of the plant is essential to be studied to analyze the various properties of the plants. Phytochemical assays are often considered to be the first step towards the discovery of useful drugs. The phytochemical profile of plantsform the basis of synthesis of many new essential drugs using those plants. A positive response of these plants for presence of bioactive compounds like Phenols, Flavonoids, Terpenoids, Tannins, may indicate that

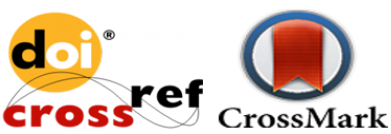


the plants can be used in detection of the bioactive principles and further may lead to drug discovery and development (V. Nandagoapalan, et al., 2016).

Phenols are one of the main secondary metabolites present in the plant kingdom. They are commonly found in plants and have shown to possess several biological activities like antioxidant activity. They are essential for the growth and reproduction of plants, and are produced as a response for defending injured plant against pathogens. Flavonoids are another important class of compounds in plants which are important in plants for normal growth development and defense against infection and injury. Like phenols, flavonoids show several biological activities like anti-allergic, antiinflammatory, anti-microbial activity. Researchers have become interested in flavonoids and other phenolics for their medicinal properties. Over 5000naturally occurring flavonoids have been characterized from various plants (Khatiwora E, 2010). Considering the importance of phytochemicals and bioactive compounds in plants and the need to study them, the present work is design to investigate the phytochemical screening and to evaluate total phenol and total flavonoid content of two weed plants i.e. Ipomoea carnea and Alternanthera sessilis.

\section{Materials and Methods}

Selection and collectionof Plant Materials:

Mature Plants of Ipomoea carnea and Alternanthera sessilis were taken for the study. Leaves of the above plants were collected randomly from Mumbai region, India. The leaves were stored in a polythene bag until they were brought to the lab for analysis.

\section{Preparation of powdered extracts of the plants:} Mature leaves of the plants were first washed in sterilized distilled water to remove any dust and dirt present on the surface. The leaves were then surface sterilized to kill the surface organisms by washing it in mercuric chloride solution $(0.1 \%)$. The leaf material was dried in an oven at $40^{\circ} \mathrm{C}$, till a constant weight was obtained. The dried leaves were later crushed in a coarse powder using ahomogenizer. The powder was passed through a sieve to obtain a homogenized powder. This powdered extract was stored in an amber colored bottle at room temperature until it was subjected to soxhlet extraction. (Jain A. et al., 2016)

Extraction of phytochemicals using Soxhlet extraction:

Extraction was carried out as suggested by Ahlem Rebaya et al., 2014 and Dorcas B James et al., 2016.

\section{Preliminary phytochemicals screening:}

The crude extracts of Ipomoea and Alternanthera were dissolved in 10\% DMSO in order to prepare a stock solution. The obtained stock solution was used for phytochemical screening. Phytochemicals like Proteins, Carbohydrates, Flavonoids, Glycosides, Saponins, Alkaloids, reducing Sugar, phenols were analyzed. (A. M. Patil, 2015) Terpenoids, Tannins, Steroids, Emodins, Anthocyanins, Leucoanthocyanins, Quinones, Coumarin were also analysed. (S. Komathi, 2015), (N. Savithramma, 2011). Determination of total phenols by Folin-reagent method. The Phenol content of plants was evaluated quantitatively by Folin-Ciocalteau method. (Mohammed et al., 2013, Esha rami et al., 2014 and Tekeshwar Kumaret al., 2015) Total phenol Content was expressed as mg of Gallic acid equivalent based on the calibration curve.

Determination of total flavonoid by colorimetric method:

The flavonoid content of plants was determined by Aluminium chloride colorimetric method. (Mohammed et al., 2013, Esha Rami et al., 2014, Tekeshwar Kumar et al., 2015) The flavonoid content was expressed as $\mathrm{mg}$ of quercetin equivalent (QE)/g dry weight of weeds.

\section{Results}

The mass obtained after soxhlet extraction and evaporation was a dark sticky mass. The mass was dissolved in DMSO and the extracts prepared were used to carry out qualitative analysis. The plant extracts showed presence of some secondary metabolites whereas they showed a negative result for few metabolites. Both Ipomoea and Alternanthera showed a positive response for metabolites Proteins, Carbohydrates, Flavonoids, Glycosides, Terpenoids, Tannins, Phenols and Reducing sugars. These are major secondary metabolites present in plants which are responsible for several medicinal properties of the plants. The extracts of Ipomoea and Alternanthera showed a negative response for Saponins, Alkaloids, Quinones, Coumarins, Emodins, Steroids, Anthocyaninans, Leuco anthocyanins. Both the plants had the same secondary metabolites present in them. In the table given below, ' + ' and '-' indicates presence and absence of that phytochemical respectively.

\begin{tabular}{ccc}
\hline Phytochemicals & IC & AS \\
\hline Proteins & + & + \\
Carbohydrates & + & + \\
Flavonoids & + & + \\
Glycosides & + & + \\
Terpenoids & + & + \\
Phenols & + & + \\
Tannins & + & + \\
Reducing Sugar & + & + \\
Saponins & - & - \\
Alkaloids & - & - \\
Quinones & - & - \\
Coumarins & - & - \\
Emodins & - & - \\
Steroids & - & - \\
Anthocyanins & - & - \\
Leucoanthocyanins & - & - \\
\hline
\end{tabular}


Ipomoea and Alternanthera extracts were subjected to phytochemical assays to determine the Total Phenol Content and Total Flavonoid Content of the leaf extracts. The phenol content was determined by Folin-Ciocalteau method where the extracts were treated with Folin reagent and $\mathrm{Na}_{2} \mathrm{CO}_{3}$. Gallic acid was used as the standard for this assay (figure 1). Absorbance was taken at 765 $\mathrm{nm}$ using U.V spectrophotometer. The present study reveals the phenol contents of the leaves of both plants in terms of $\mathrm{mg}$ Gallic acid equivalent/g of dry sample (sample plot: $\mathrm{R}^{2}=0.9947$ ). The value obtained for total phenol content for $I$. carnea was $0.0526 \mathrm{mg}$ Gallic acid equivalent/g and the value for A. sessilis was $0.0657 \mathrm{mg}$ Gallic acid equivalent/g.

The Flavonoid Content was determined by Aluminium chloride method where the extracts were treated with $\mathrm{AlCl}_{3}$ and Potassium acetate. Quercetin was used as a standard for this assay (figure: 2). The values obtained for were expressed as $\mathrm{mg}$ of quercetin equivalent $(\mathrm{QE}) / \mathrm{g}$ dry weight of the plants (sample plot: $\mathrm{R}^{2}=0.9176$ ). Absorbance was taken at $415 \mathrm{~nm}$ using U.V spectrophotometer. The total flavonoid content value obtained for $I$. carnea was $0.09 \mathrm{mg}$ quercetin equivalent $(\mathrm{QE}) / \mathrm{g}$ and for $A$. sessilis was $0.2 \mathrm{mg}$ quercetin equivalent (QE)/g.

\section{Discussion}

The chemical compounds present in plants are the biologically active constituents. These biologically active compounds play a major role in various properties of plants like antioxidant, antimicrobial, anti-cancer etc. The methanolic extracts of Ipomoea and Alternanthera were tested for presence of various phytochemicals. Both the plant extracts showed presence of several chemical compounds like Phenols, Flavonoids, Tannins, Glycosides and Sugars. Presence of secondary metabolites in the two plants, indicated that these plants can be used as herbal components. Both the extracts showed a positive response for Phenols and Flavonoids. Phenols are class of compounds which are associated with the antimicrobial properties of the plants. (A. Doss, 2009) Flavonoids are another major category of compounds which are potent free Radical Scavengers and act as antioxidants. (D.E. Okvu, 2005) Several other Chemical constituents like Proteins, Carbohydrates, Glycosides, Terpenoids, Tannins and Reducing sugars were also found to be present in both the plant extracts.

Tannins are known to have stringent properties which hasten the healing process of wounds. Terpenoids have been associated with antifungal, antiviral, antibacterial, anti-inflammatory and immunomodulatory properties. Glycosides have vast therapeutic effect and they are found in almost all medicinal plants. Plants rich in proteins and carbohydrates are beneficial as dietary supplements as they boost immunity. (Manjulika Yadav, et al., 2014)

In the present study, the total phenolic content was determined by slight modification of established protocol and the results were expressed in terms of $\mathrm{mg}$ Gallic acid equivalent/g of dry sample. Among the two weeds tested, extracts of Alternanthera contained higher phenol content as compared to Ipomoea carnea. Total flavonoid content of the extracts was determined by modification of the protocol suggested by Illa Patel, 2014. The measured values were expressed in terms of Quercetin equivalents per gram of dried sample. The plant extracts of Alternanthera sessilis showed a higher amount of Flavonoids as compared to Ipomoea extracts.

Previous studies on Phenol and Flavonoid content have been conducted on Alternanthera sessilis by $R$. Sivakumar, 2016 and Lalitha Sree T, 2016.However the study was conducted onethanolic and aqueous extracts of Alternanthera sessilis and not methanolic extracts. Similar studies were done for Ipomoea carnea by Elija Khatiwora et al., 2010 and K. Sahayaraj, 2008.However, these studied considered the acetone, benzene and ethanol extracts of the leaves of the plant.

Our results indicate that both the plants selected for study displayed a good concentration of Flavonoids and Phenols. As per our study, Alternanthera extracts contained higher total phenolic and total flavonoid content as compared to the Ipomoea extracts. Weeds are plants which are usually neglected for studies as they are considered as unimportant plants. Presence of secondary metabolites in such plants can be useful as such weeds can be exploited and used for several beneficial purposes. Phytochemical analysis is the first step in identifying the usefulness and benefits of a plant. A positive response for several major phytochemicals can be an indication that the plant can be used for medicinal or other therapeutic purposes. Also the phytochemicals present in these plants may be responsible for them to show allelopathic effect.

\section{Acknowledgements}

The authors would like to acknowledge the JIGYASSA SCIENCE HONORS PROGRAM at K.C College, Maharashtra 400050, India.

\section{References}

1. Doss, Preliminary phytochemical screening of some Indian Medicinal Plants, Ancient Science of Life, 2009, $29(2), 12-16$

2. Abhinav A. Mali and M. B. Kanade, Allelopathic effect of two common weeds on seed germination, root-shoot 
length, biomass and protein content of jowar, Annals of Biological Research, 2014, 5 (3):89-92.

3. AhlemRebaya, Souad Igueld Belghith, Béatrice Baghdikian, Valérie Mahiou Leddet, Fathi Mabrouki, Evelyne Olivier, Jamila kalthoum Cherif, Malika Trabelsi Ayadi, Total Phenolic, Total Flavonoid, Tannin Content, and Antioxidant Capacity of Halimiumhalimifolium (Cistaceae), Journal of Applied Pharmaceutical Science, 2014, 5 (01), 052-057.

4. D.E. Okvu, Phytochemicals, Vitamins and Mineral Contents of Two Nigerian Medicinal Plants, International Journal of Molecular Medicine and Advance Sciences, 2005, 1(4), 375-381

5. Esha rami, Illapatel, Quantitative analysis of total phenols and flavonoids in In vivo and In vitro samples of oroxylumindicum(1.) vent, Asian J Pharm Clin Res, 2014, 8(2),202-204.

6. Jain, A., Roy, S., Joshi, A., \& Joshi, N., Evaluation of In-vitro cytotoxic and antioxidant activity of methanolic extracts of Ipomoea carnea and Alternanthera sessilis. International Journal of Bioassays, 2016, 5(08), 4763-4766.

7. K. Sahayaraj, C. Ravi, Preliminary Phytochemistry of Ipomea carnea jacq. andvitexnegundolinn. leaves, Int. J. Chem. Sci.,2008, 6(1), 1-6.

8. Khatiwora, E., B. Adsul, V., M. Kulkarni, M., R. Deshpande, N., \& V Kashalkar, R., Spectroscopic determination of total phenol and flavonoid contents of Ipomoea carnea. International Journal of Chemtech Research, 2010, 2(3), 1698-1701.

9. LalithaSree T and K. Vijayalakshmi, Phytochemical screening and quantitative analysis of bioactive components in various extracts of Alternanthera sessilis linn Leaves, IJCPS, 2016, 4(5): 242-246.

10. ManjulikaYadav, SanjuktaChatterii, Sharad Kumar Gupta and GeetaWatal, Preliminary Phytochemical screening of six medicinal plants used in TraditionaL Medicine, International Journal of Pharmacy and Pharmaceutical Sciences, 2014, 6(5).

11. Mohamed Abd El-AalLotfySadek, Impact of the Invasive Ipomoea carnea Jacq. on Plant Diversity Along the Canal and Drain Banks of Nile Delta, Egypt, CATRINA,2014, 11 (1), 33-40.

12. Mohammed, Salmin K. Alshalmani and AwadGiummaAbdellatif, Antioxidant and Quantitative Estimation of Phenolic and Flavonoids of Three Halophytic Plants Growing in Libya Hamdoon, Journal of Pharmacognosy and Phytochemistry, 2013, 2 (3): 8994.
13. N. Savithramma, M. Linga Rao and D. Suhrulatha, Screening of Medicinal Plants for Secondary Metabolites, Middle-East Journal of Scientific Research, 2011, 8 (3): 579-584.

14. Nitesh Joshi, Neha Nangia and Ambika Joshi, Seed germination studies on allelopathic effects of weeds on vignaradiata L, Int. J. Bioassays, 2015, 4 (02), 3664-3666

15. Patil, M., and SaheraNasreen. "Screening for Secondary Metabolites of Some Important Medicinal Plants". Paripex - Indian journal of research, 2015, 4.8.

16. R. Sivakumar and D. Sunmathi, Phytochemical Screening and Antimicrobial activity of ethanolic leaf extract of Alternanthera sessilis (L.) and Alternanthera philoxeroides (mart.) 2016, 3(3), 409-412.

17. S. Komathi and M. FernandusDurai, Qualitative Phytochemical Screening of SaccharumspontaneumLinn. Leaf Extracts, Journal of Academia and Industrial Research (JAIR), 2015, 4(6),168-170

18. Sharma, A and Bachheti, RK., A review on Ipomoea carnea. Int J Pharm BioSci, 2013, 4(4), 363 - 377.

19. Singh, A., Kandasamy, $\mathrm{T}$ and Odhav, B., In vitro propagation of Alternanthera sessilis (sessile joyweed), a famine food plant. African Journal of Biotechnology, 2009, 8 (21), 5691-5695.

20. Stanley Irobekhian Reuben Okoduwa, Ismaila A Umar, Dorcas B James, Hajara M Inuwa, and James D Habila, Evaluation of extraction protocols for antidiabetic phytochemical substances from medicinal plants, World J Diabetes, 2016,7(20), 605-614.

21. Tekeshwar Kumar, Vishal Jain, Appraisal of Total Phenol, Flavonoid Contents, andAntioxidant Potential of Folkloric Lanneacoromandelica Using In vitro and In vivo Assays, Hindawi Publishing CorporationScientifica, 2015, Volume 2015, 1-3.

22. UdayaPrakash NK, Bhuvaneswari S, Aravind R, Kaviyarasan V, Kalaivanan K, Hariram SB, A Comparative study on antibacterial activity of common weeds, IJPBS, 2011, 2(1), 677-683.

23. V. Nandagoapalan, A. Doss and C. Marimuthu, Phytochemical Analysis of Some Traditional Medicinal Plants, Bioscience Discovery, 2016, 7(1):17-20.

\section{Cite this article as:}

Shah Shreshtha, Jain Anushi, Joshi Ambika, Joshi Nitesh, Harshal Anupma. Study of total phenol, flavonoid contents and phytochemical screening of methanolic crude extracts of two weed plants. Annals of Plant Sciences 6.6 (2017) pp. 1645-1648.

DOI: http://dx.doi.org/10.21746/1651-1654 